\title{
Tricky Design Probes
}

\section{Triggering Reflection on Design Research Methods}

\section{Anaëlle Beignon ${ }^{1,2}$, Emeline Brulé ${ }^{3}$, Jean-Baptiste Joatton ${ }^{1}$, Aurélien Tabard ${ }^{2}$ *}

${ }^{1}$ Pôle supérieur de design

Villefontaine, France

anaellebeignon@gmail.com

jean-baptiste.joatton@ac-grenoble.fr

\section{ABSTRACT}

Design research methods are increasingly used as ready-made recipes for success in a variety of fields and multidisciplinary teams. Yet as any tools, they shape the gaze, attitudes, and behaviors of designers. Moreover, their generic nature tends to obscure the specific situations in which they were created. In reaction, grounding our work in adversarial design, we propose four tricky probes: believable design tools, which appear to be innocuous, but progressively engage designers in crossing boundaries of what should be acceptable. This is done by slowly derailing design research activities, leading to trigger reflection on the part of designers on their beliefs, practice, and the tools they use. Our probes raise issues at the intersection of design research and gender in urban service design, such as the use of pre-made algorithms to understand gendered patterns in urban movements.

\section{Authors Keywords}

design tools; design research; critical design; adversarial design; gender; probes.

Permission to make digital or hard copies of all or part of this work for persona or classroom use is granted without fee provided that copies are not made or distributed for profit or commercial advantage and that copies bear this notice and the full citation on the first page. Copyrights for components of this work wermitted To copy otherwise, or republish, to post . Abstracting with credit is o lists, requires prior specific permission and/or a fee. Request permissions from Permissions@acm.org. C) 2020 Copyright is held by the owner/author(s). Publication rights licensed to ACM.

ACM ISBN 978-1-4503-6974-9/20/07 \$15.00

https://doi.org/10.1145/3357236.3395572
* Listed by alphabetical order - the authors contributed equally

2Univ Lyon, Université Lyon 1, CNRS, LIRIS, UMR5205

F-69621, France

aurelien.tabard@liris.cnrs.fr

\section{INTRODUCTION}

In the last decades, design toolkits for research or ideation have found their way into businesses, educational settings, urban planning [25], and social policy organisations $[1,22]$. In order to be useful across domains, these toolkits have to be generic, detached from their context of creation and application, or what Suchman would call "design from nowhere" [28].

These toolkits often aim at rapidly synthesizing and building consensus on a given issue, relying on carefully calibrated empathy and participation [21]. In doing so they tend to avoid critical considerations that could undermine the projects' expected outcomes [17, 25]. For instance, projects might ignore the point of view of marginalised communities [16]. The participatory design scholarship has long highlighted the challenges of supporting social change [6] while creating space in which different experiences, as well as the tensions and disagreements that can not be resolved, can be discussed $[4,5]$.

To ignite and sustain these discussions, some researchers and designers have embraced adversarial design approaches. Instead of using design methods in political processes aiming at identifying a consensus, adversarial design seeks to "open a space for contestation; and it suggests new practices of design." [10 p.9] This includes critical and speculative design approaches, which most often involve creating thoughtprovoking design pieces, then exhibited to foster reflection on beliefs, values and problem framing [22].

\author{
${ }^{3}$ University of Sussex \\ Falmer, United Kingdom \\ e.t.brule@sussex.ac.uk
}

However, this does not bring the critique to the everyday design process itself - where values are being generated and negotiated-therefore missing out on supporting designers in opening spaces of contestation. To do this, we propose to use probes [13]. Probes are a generative and narrative method, often used to inspire the designer, or reveal potential new practices when deploying voluntarily unfinished artifacts [7]. They are usually used to learn and reflect about participants and the design context, but not for designers to learn about themselves.

In this pictorial, we propose probes that build on critical design to question designers' own practices. We call them tricky design probes: seemingly genuine and innocuous design tools through which designers explore, or encourage others to explore, boundaries and controversial aspects of their methods for the problem they aim to tackle. We design and deploy four probes to address designers' socio-political constructs regarding gender, and question design tools used in urban planning and urban informatics projects: (1) Gender classification and large-scale sensor systems (2) Politics of risk and the convenience of design workshops (3) Street harassment and empathy (4) Street harassment and design guides. We reflect on how each probe enabled to question the project framing and methods, in both expected and unexpected ways. Tricky design probes are helpful to practitioners wishing to highlight ethical issues to colleagues and participants, and can open new areas of inquiry for research on probes and critical design. 


\section{GENDER CLASSIFICATION AND LARGE- SCALE SENSOR SYSTEMS}

\section{Design methods in question}

Designers increasingly rely on tracking data to generate insights into people's behaviors. This ranges from analytics tools, to emerging bio-signal and biometric monitoring based on video analysis, e.g. emotion inference or face-recognition. This large scale data collection is presented as a highly effective way for designers to get reliable insights on user behavior.

\section{The problem}

As data gets collected on a large scale, it must be processed and synthesized to draw any form of insights. This algorithmic treatment involves aggregation, filtering, clustering, and summarization techniques in order to recognize stereotypical traits or personas. With this probe, we focus on the issue of identifying and categorizing activities of women. When it comes to gender, activists have long recognized both the needs to identify statistical gender differences [26] but also to go beyond the gender binary [15]. By offering a probe that enables designers to experience this tension we seek to make this problem tangible. Moreover, we also seek to raise the issue of data being collected without full informed consent, and how it can be leveraged by external actors to secure their say on the design of services or even future cities [8].
The probe

This probe engages designers in confronting how they stereotype users, and to discuss whether surveillance technology can be ethically leveraged to gain insights.

We collected snapshots from four public surveillance cameras recording squares or streets from around the world. We set-up the probe as an installation. And we asked designers to classify people on snapshots in two categories: male or female.

1 To set the stage, a strip hangs from the ceiling enabling to scroll through 24 hours of snapshots captured from a street camera. On the wall, further snapshots reinforce the feeling for monitoring and surveillance.

2 On the table, a notebook lets designers enact the gender classification algorithm by grading genderstereotypical criteria used to assign a gender to people in the video.
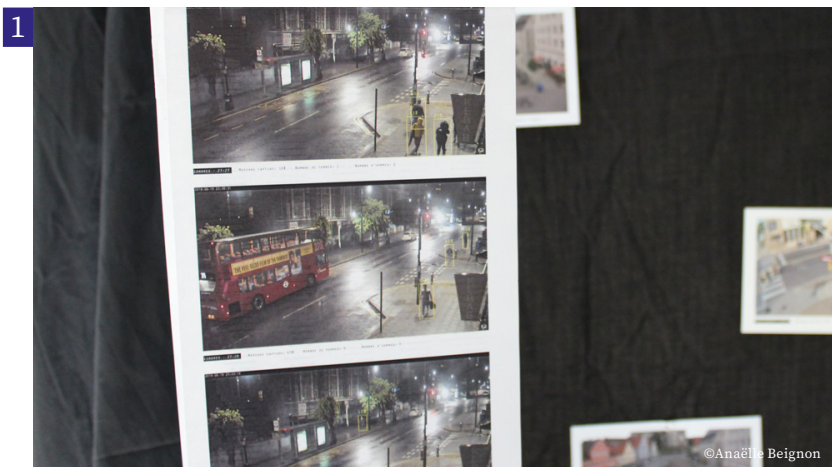
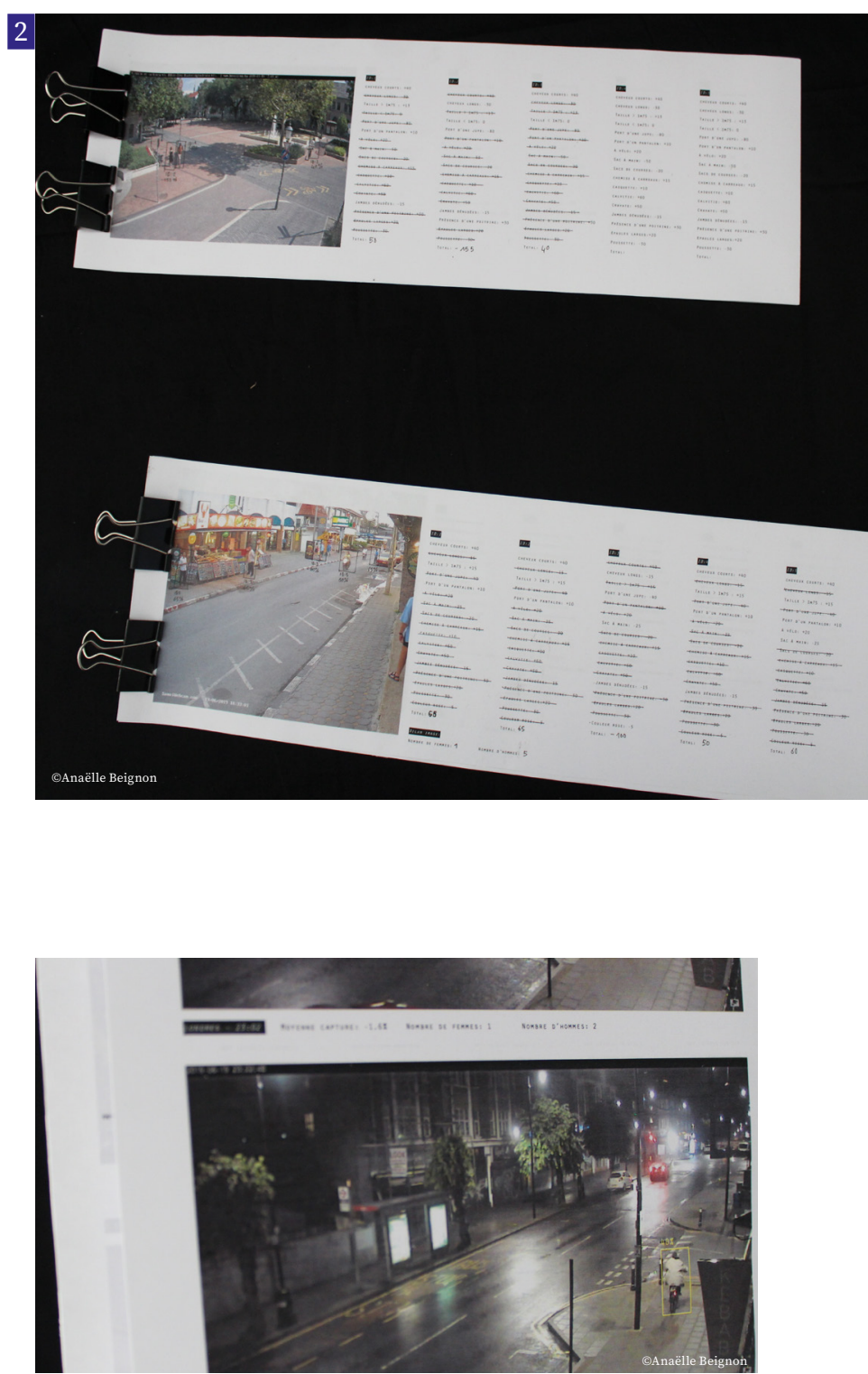


\section{Training the recognition algorithm}

In order to process data collected on a large scale, automated analysis becomes mandatory. These automated methods typically rely on machine learning techniques that are trained on a subset of the data and will propagate the gaps, limitations and biases of the initial categorization and training.

We structured the experience in two stages, with the first author and two design students manually training a gender recognition algorithm.

1 The first author created a first set of criteria and associated weights. The criteria could be broadly categorised as 'physiological' (e.g. height) and 'cultural' (e.g. uses a stroller, type of clothing). Each criterion had a weighting (e.g. -30 or +50 ). Criteria associated with women had a negative weight, whereas criteria associated with men had a positive weight.

2 The participants then "trained" the algorithm by adding or removing criteria, or changing their weight, in order to successfully classify the gender of people in the surveillance camera pictures presented to them.

3 Then participants repeated this process on a series of printed screenshots. At this stage, they could only apply the criteria and weights used defined in the training phase.

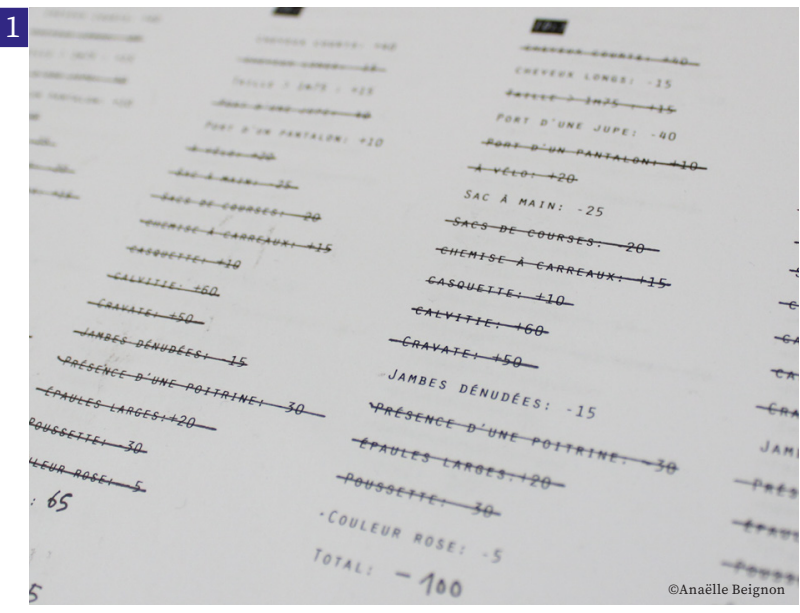

FIRST AUHOR'S INITIAL

VERSION OF THE ALGORITHM:

SHORT HAIR: +40

LONG HAIR: -30

HEIGHT > 1M75: +13

HEIGHT < 1M75: 0

WEARING A SKIRT: -80

WEARING PANTS: +10

BY BIKE: +20

HANDBAG: -50

SHOPPING BAGS: -20

PLAID SHIRT: +15

CAP: +10

BALDNESS: +60

TIE: +50

BARE LEGS: -15

PRESENCE OF A BREAST: + 30

WIDE SHOULDERS: +20

STROLLER: -30
FIRST AUHOR'S VERSION

AFTER THE TRAINING:

SHORT HAIR: +40

LONG HAIR: -25

HEIGHT $>1$ 1M75: + +15

WEARING A SKIRT: -40

WEARING PANTS: +10

BY BIKE: +20

HANDBAG: -25

SHOPPING BAGS: $=20$

PLAID SHIRT: + 15

CAP: +10

BALDNESS: +60

TIE: +50

BARE LEGS: $=15$

PRESENGE OF A BREAST: + 30

WIDE SHOULDERS: - 20

STROLLER: -30

PINK COLOR: -5
VERSION OF THE

PARTICIPANTS

(2 DESIGNERS):

SHORT HAIR: +50

LONG HAIR: -25

FACIAL HAIR: +40

DYE: -30

SHIRT: +20

HEADGEAR: +20

PANTS: +20

DRESS OR SKIRT: -50

PANTS: +10

BACKРACK: +20

CLOSED SHOES: +10

OPEN SHOES: -20

TWO WHEELS: +25

STROLLER: -50

PINK: -15
CrTmera Detemed-TM-THE NEXT ENACTMENT OF THE ALGORITHM

CRITERIA OR VALUE MODIFIED IN THE NEXT ENACTMENT OF THE ALGORITHM

CRITERIA ADDED IN THE CURRENT ENACTMENT OF THE ALGORITHM
3

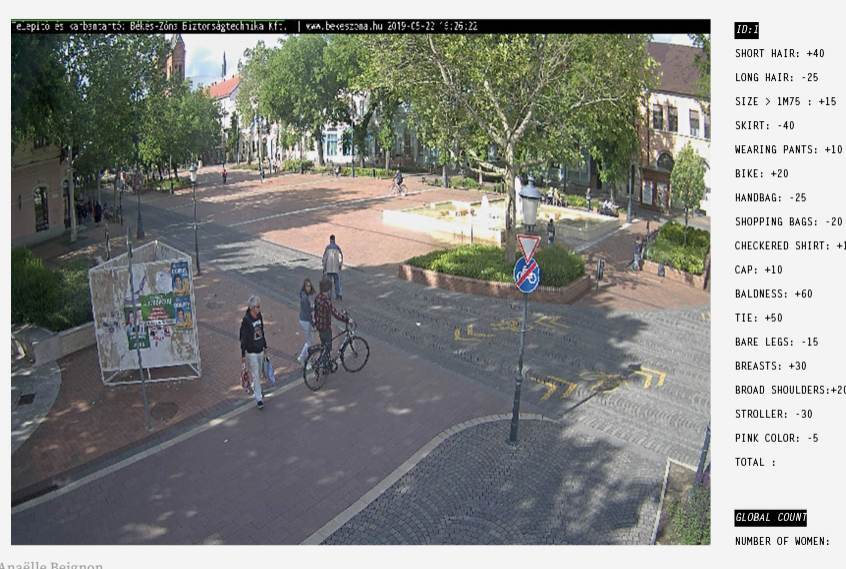

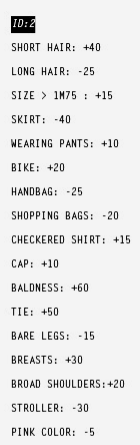

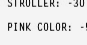

NUMEER OF MEU. $\underset{\text { SHoRT }}{\text { WD: }}$

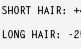
SIIIE) 1 1975 : + + SRLRT: 40 MERRING PANTS
BIKE: +200 BAMNOAGS + 25 SHopprng BaSS: -20

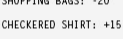
CAP: +10 BMLONESS: +60 TIE: 750

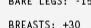
BRPAD SHOULDERS + + STROLLER: - 30 PINK COLOR: orat :

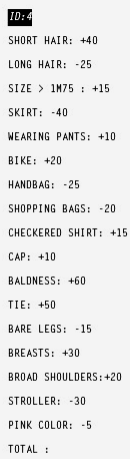

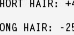
SIIE > 1975 : +15 SKRRT: : 40

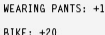

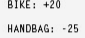
SHOPPIIG BASS - 20

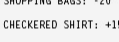
CAP: +10 BADDNESS: +60 TIE: 750

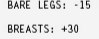
BPRAD SHOULLERS STroulLeR: - 30 PIIIK COLOR: -5 


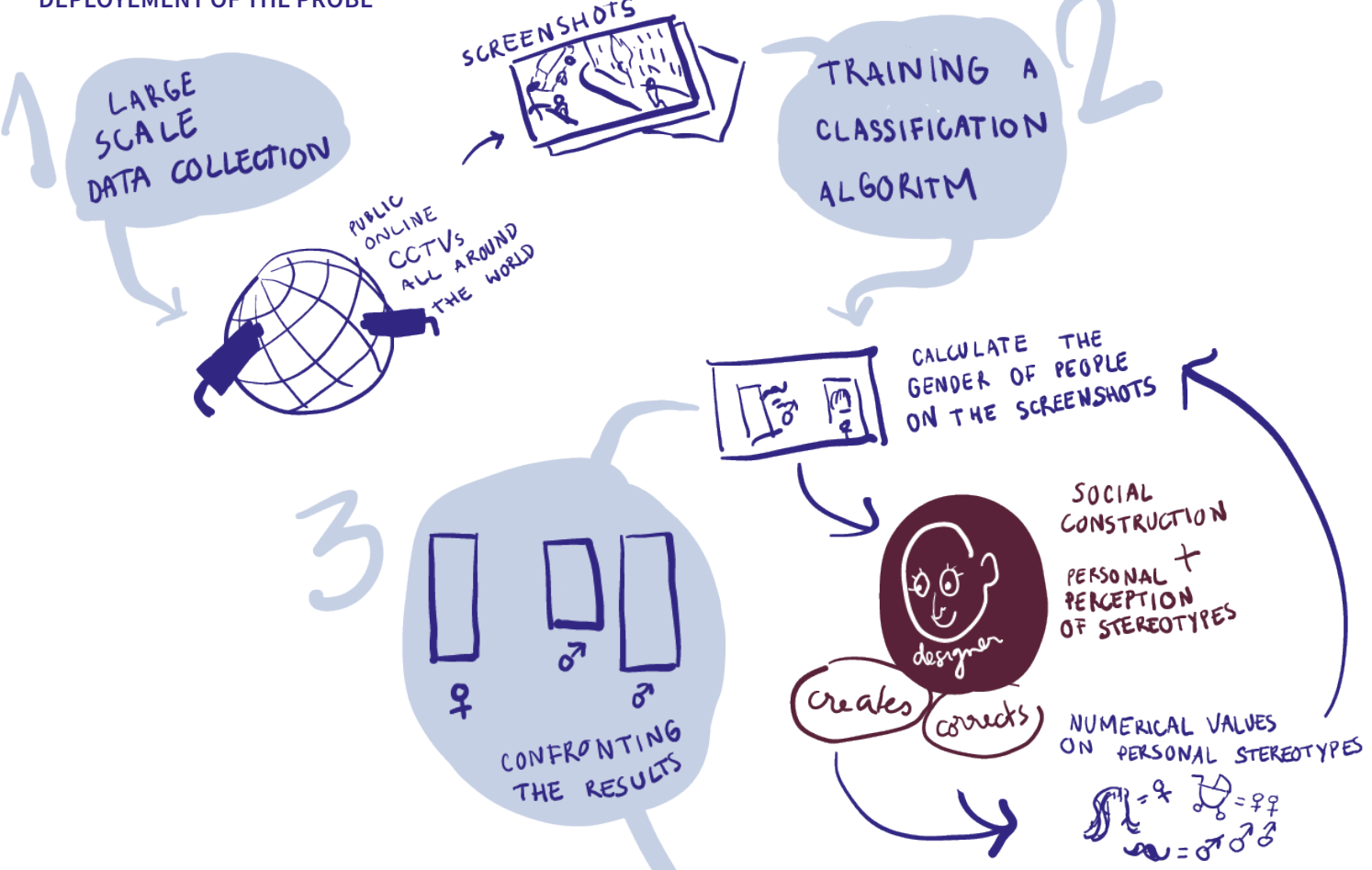

QUESTIONS RAISED BY THE PROBE

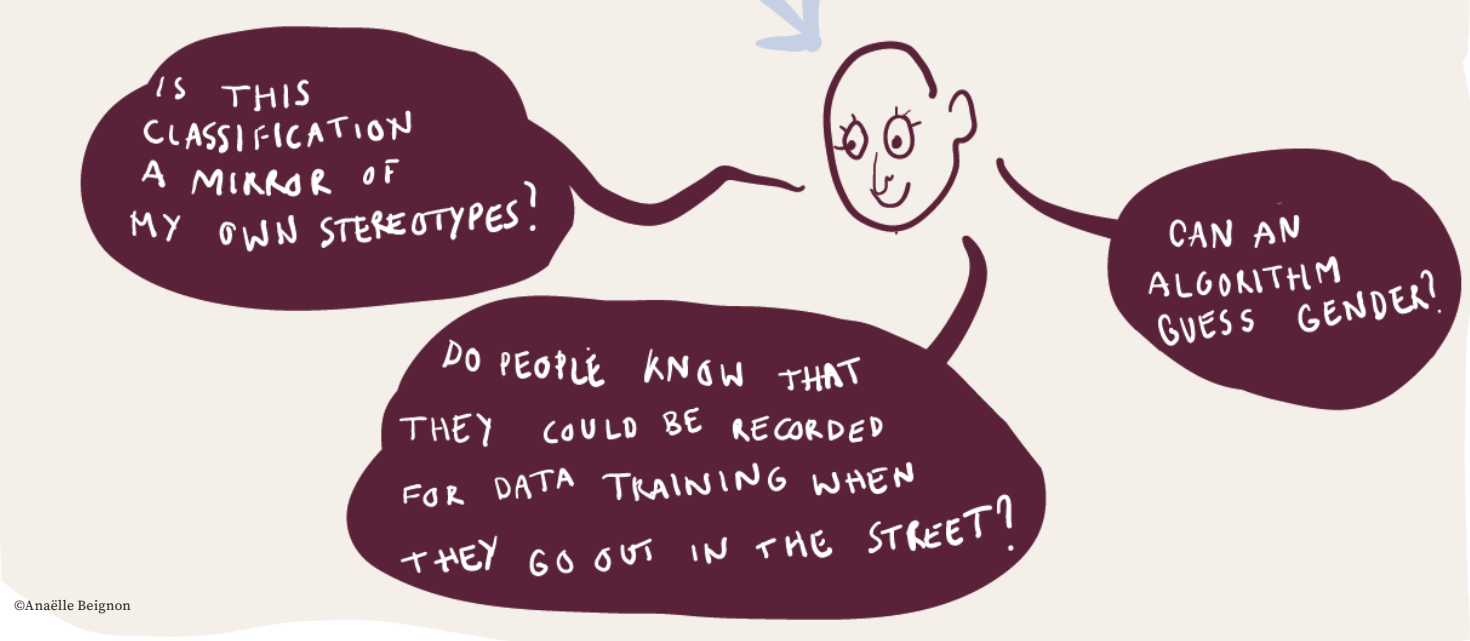

\section{Supporting reflexivity on wide-scale data harvesting}

The probe questions the effectiveness of analytics and algorithmic treatments to "understand users", by repurposing the quintessential surveillance device: street cameras. Applying it to gender identification, the probe further questions whether this approach is not disturbingly making the participant effectively sexist for the sake of efficiency.

1 We collected images from different public spaces around the world at different times in order to analyse the people appearing on them. Picking surveillance cameras makes the question of surveillance-based data collection for design purposes much more salient.

2 We asked participants to build and train together the algorithm, that required them to agree and discuss their stereotypes. The first author and the two designers initially strengthened the impact of clothing and activities criteria - strollers, dresses. This activity generated absurd discussions on gender norms (e.g. on the reasons for including closed shoes as a criterion for masculinity).

3 In the last stage of the algorithm, we asked participants to count people recognized as men and women with the algorithm. This led to a visual trace on paper of the participants' stereotypes. Although the final pick is binary, the linear scale from $-\mathrm{XX}$ to $+\mathrm{YY}$ suggests that the categorization process is not so clear.

Enacting a simple algorithm reveals the stereotype involved on a daily basis to define gender identity. The probe led us and participants to discuss the ambivalence of stereotypes, they may accurately describe a significant proportion of the population, i.e., how conforming they may be, but they also reduce people to a narrow number of arbitrary and superficial criteria. By extension, the probe questioned the way analytics are used on an everyday basis by the profession all around the world, while they are convenient, cameras from openly accessible feeds, further raise the question of consent of the people being analyzed. 


\section{POLITICS OF RISK AND THE CONVENIENCE OF DESIGN WORKSHOPS}

\section{Design methods in questions}

Workshops are a method of choice to involve nondesigners participants in design activities. They often involve clients or stakeholders alongside design teams. Consulting firms and design thinking facilitators heavily rely on workshops activities involving spatial or experience mapping, and post-it sorting [21]. They dispose of a wealth of resources often building on gaming mechanics and artefacts such as cards deck [14] to lead engaging workshops.

\section{The problem}

In the $60 \mathrm{~s}$, based on experiences in urban planning, Arnstein identified the many forms participation can take, ranging from low levels of control and participation to high levels of citizen control [1]. Design workshops, and more generally participatory design aimed at enabling high levels of involvement. Even if workshops do not only produce design artifacts but also cultural reconfiguration [12], they tend to fail to reach these standards [17] and to create meaningful social change [4]. Moreover, in urban design, the question of women's experiences is often conceptualised in terms of risks, which can lead to favor, for instance, privacyinvasive security technology. A framing we sought to question.

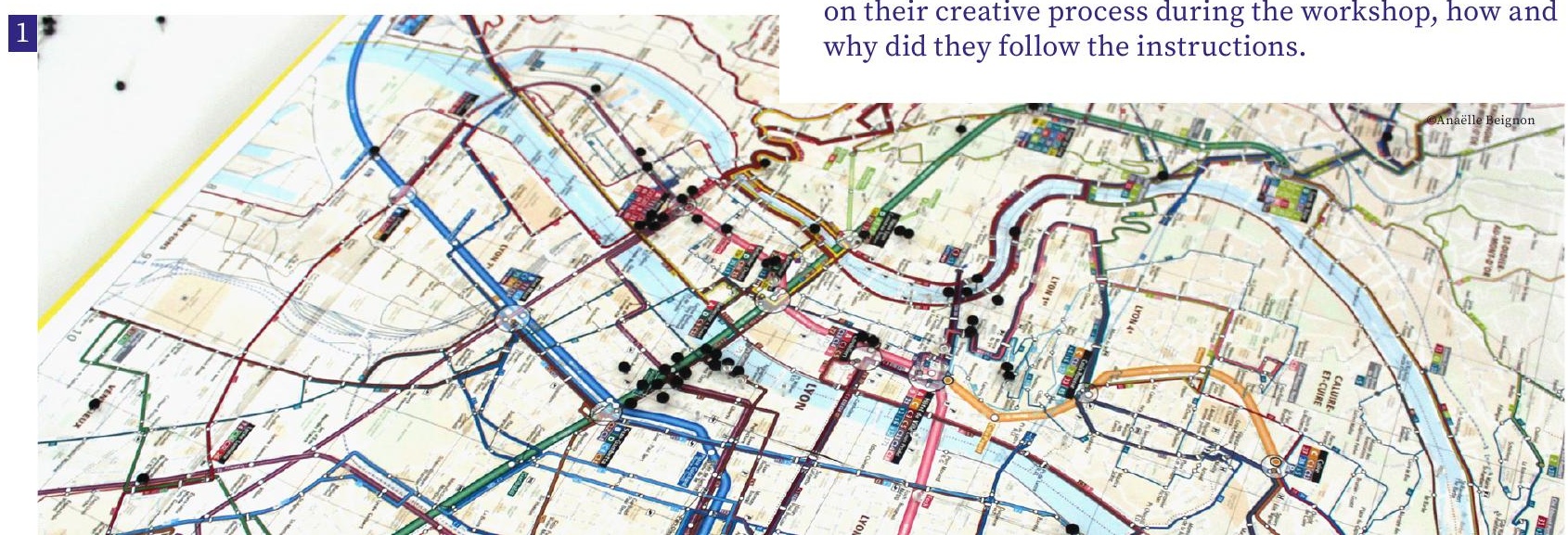

The probe

We created a workshop activity aimed at envisioning a service for improving women's mobility experience in urban areas, especially at night. The first author acted as a facilitator and invited three design students as participants. The workshop unfolded in three stages:

1 Mapping the positive and negative events they encountered on a map of the city they live in. Participants used black pins for negative experiences, and transparent pins for positive ones. Most events were unpleasant and the facilitator referred to them more often than to their positive counterparts.

2 Building on the problems identified, the facilitator asked participants to design for the safety of women, thereby implying women are always in danger. We used persona cards focused on people who had problems getting home. The facilitator used constraints cards planned beforehand in order to gradually bring the participants towards the desired outcome. The facilitator was deciding on the fly if the instructions were optional or mandatory, to orient the workshop surreptitiously with very little intervention. This gave the impression that the facilitator did not intervene unless participants asked questions.

3 Presentation of the results and debrief with the participants. Being designers, we asked them to reflect on their creative process during the workshop, how and why did they follow the instructions
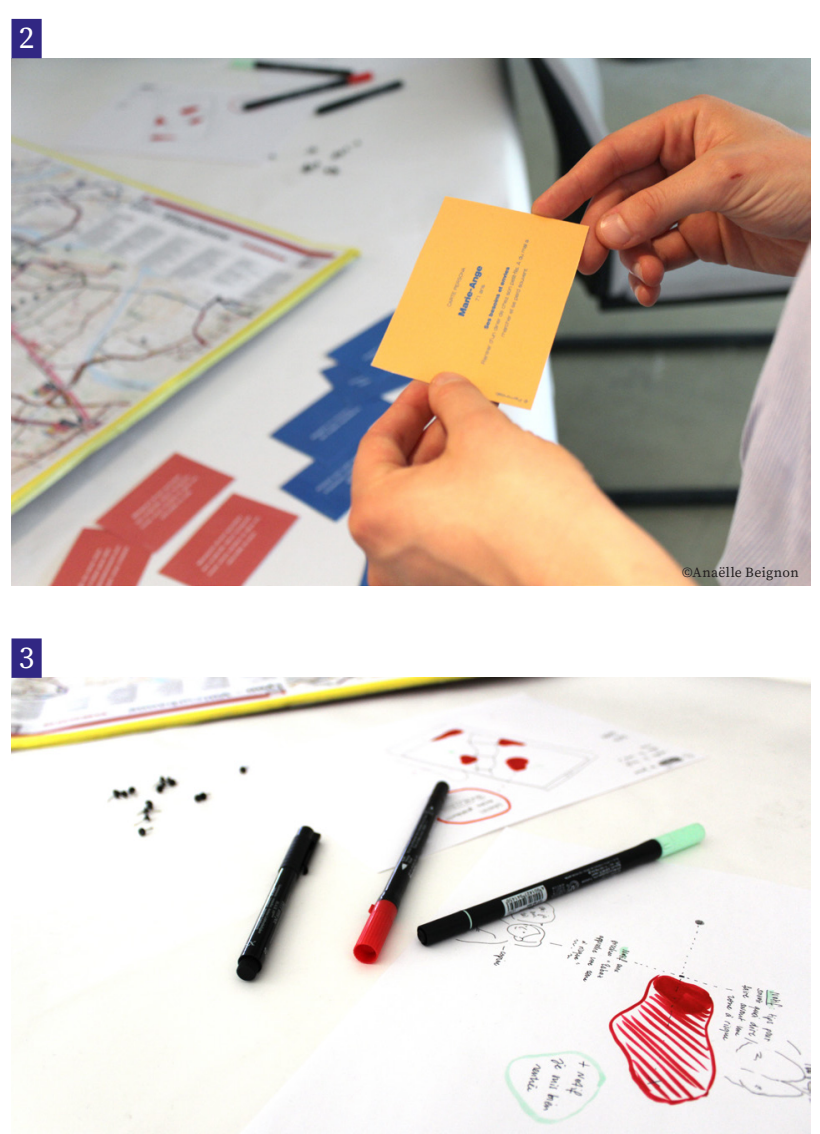
DEPLOYEMENT OF THE PROBE

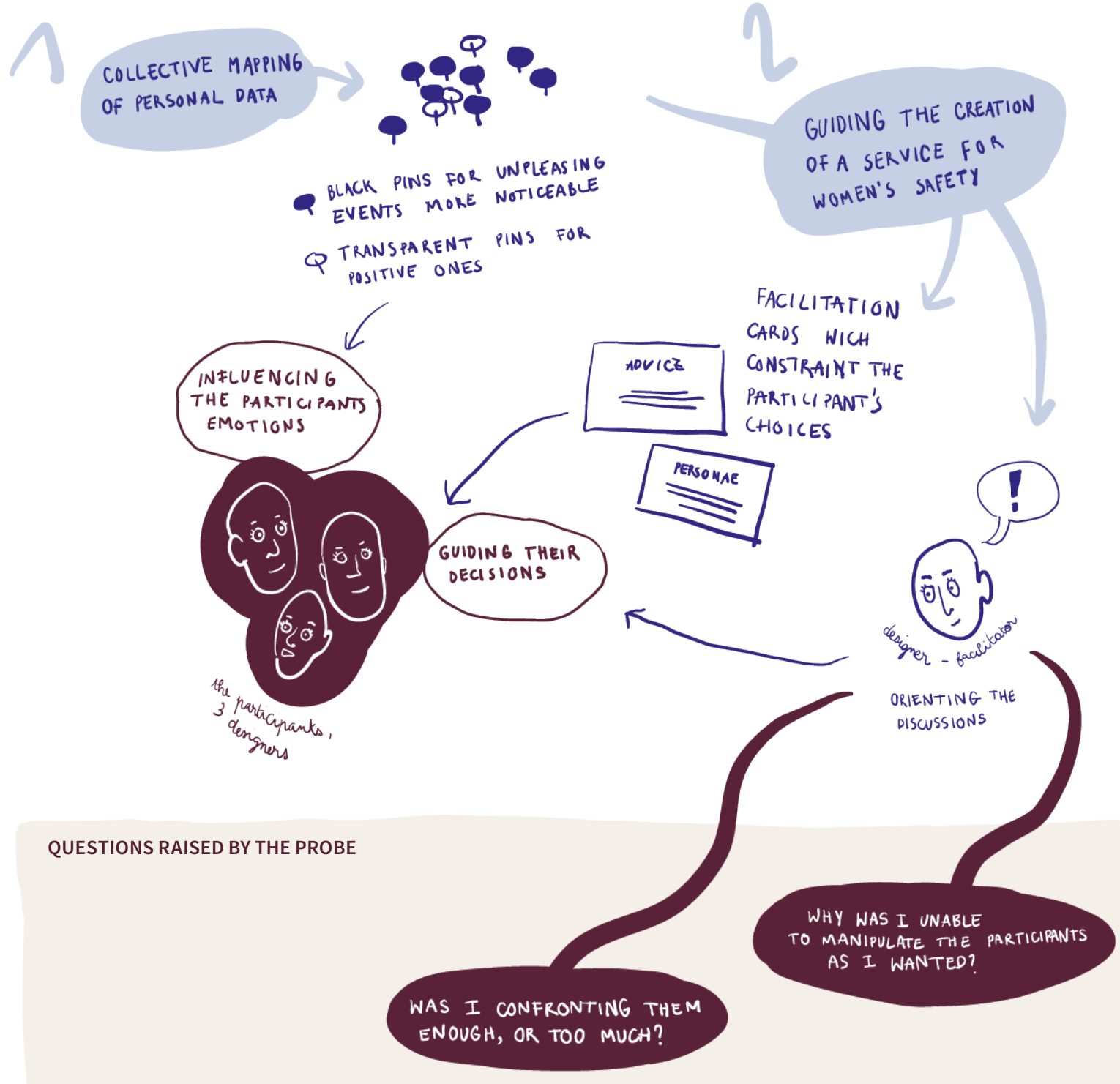

Supporting reflexivity on designer's control in participatory activity

We created the workshop as a probe to question the neutrality of design facilitators. We were particularly interested in exploring how seemingly neutral activities (placing both positive and negative experiences on a map) or randomness (drawing cards from a stack) could frame design outcomes, and orient participants towards a predefined concept.

1 Participants were highly engaged in the first phase of experience mapping, which put forward the participants' worst experiences in the city.

2 Participants followed the workshop flow until the end of the second phase. They did not confront or question the facilitator, who was progressively restricting the possible design areas using facilitation cards. They still generated a lot of ideas, even though they manifested their disapproval towards the constraints applied to them, especially towards the facilitation cards, which they seemed to perceive as useless or inadequate. The three participants, all designers, were already familiar with feminist discourse and identified that the activity was heading in a direction that was not completely aligned with their values, and saw the activity as pointless. The participants said they felt constrained during the workshop, but noted nonetheless that it was a space of creation restricted by rules and processes directed by the person in charge. This probe led us to reflect on what makes a tricky probe work, rather than reflect on design workshops and security technology. Indeed, the topic of the workshop was maybe not controversial enough, as a safety service for women might be desirable for the participants. Creating a manipulative activity to reflect on facilitation and manipulation, nonetheless led us to reflect on the complexity of participatory dynamics. By following the workshop instructions without being oblivious to the facilitators' framing. The probe reminded us that participants have agency, are not naive, but at the same time that it is challenging to question the framing of an activity as it unfolds. This suggests that there is a fine balance to find in the design of tricky probe between setting a believable activity and reaching limits that can trigger reflexivity. 


\section{STREET HARASSMENT AND EMPATHY}

\section{Design method in question}

Empathy is a central concept in design thinking and design toolkits [18]. It can be understood as the ability to understand or be sensitive to another person's feelings and thoughts. Empathy is typically developed through, interviews, shadowing, and other field research techniques [24]

\section{The problem}

The concept of empathy presupposes that designers do not share the same experiences as their informants. This questions how engaged or distanced from the subject designers should be.

We chose here to target reflexive approaches in which designers look into their own experience, and write reflexively about it, striving for authenticity, plausibility, and criticality while acknowledging limits to their study. We focused on sexual harassment and associated fears in urban environments.

\section{Be careful! You are crazy!}

Reactions from the first author's entourage when she told them about her project to make this trip

\section{Can I have your number? Where do you live? \\ Are you single? Can I kiss you?}

Extracts of dialogues recorded during the trip

\section{The probe}

The primary author created a map of her fears, and mapped areas where she felt scared and those where she felt comfortable. 1 Then she planned a trip in areas she feared, at night. She took the opposite approach to the previous probe: decided to

overcome feelings of unsafety.

1

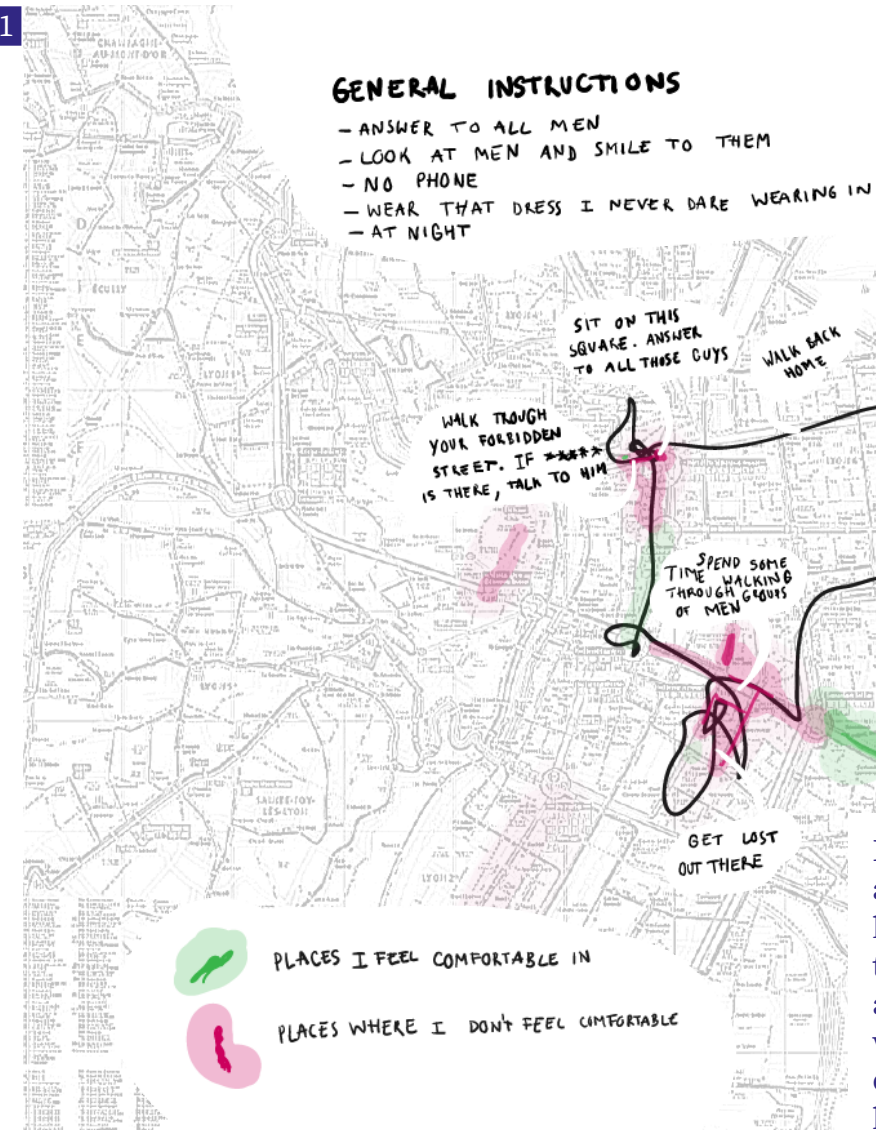

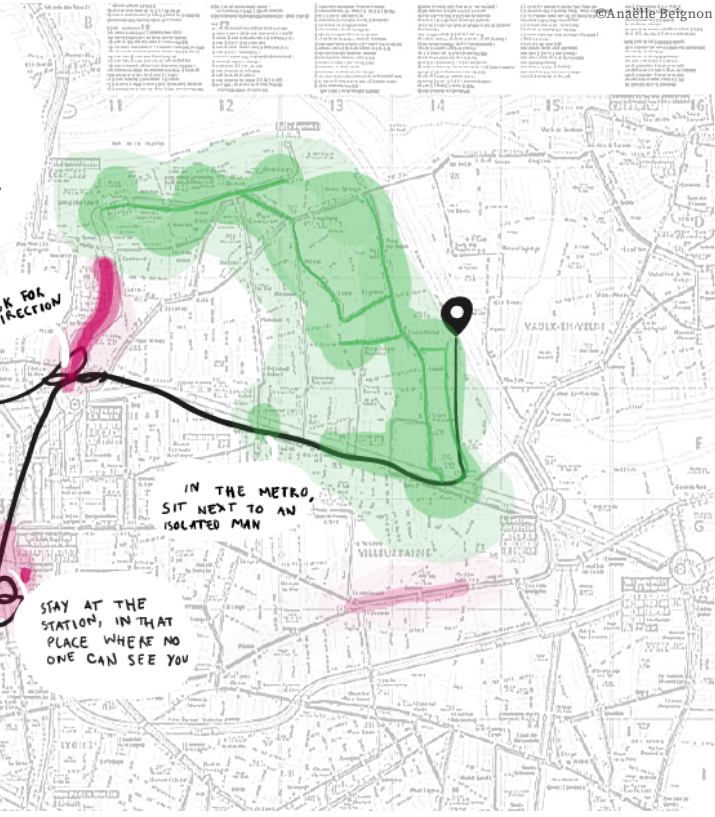

Prior to the trip she explained to designer friends and colleagues her intention to systematically study her own experiences of street harassment as a way to empathise with women. During the trip, she paid attention to her feelings and street discussions. She wrote down her feelings after the fact, and recorded the discussions she had with men during the trip, and with her relatives and friends beforehand. 


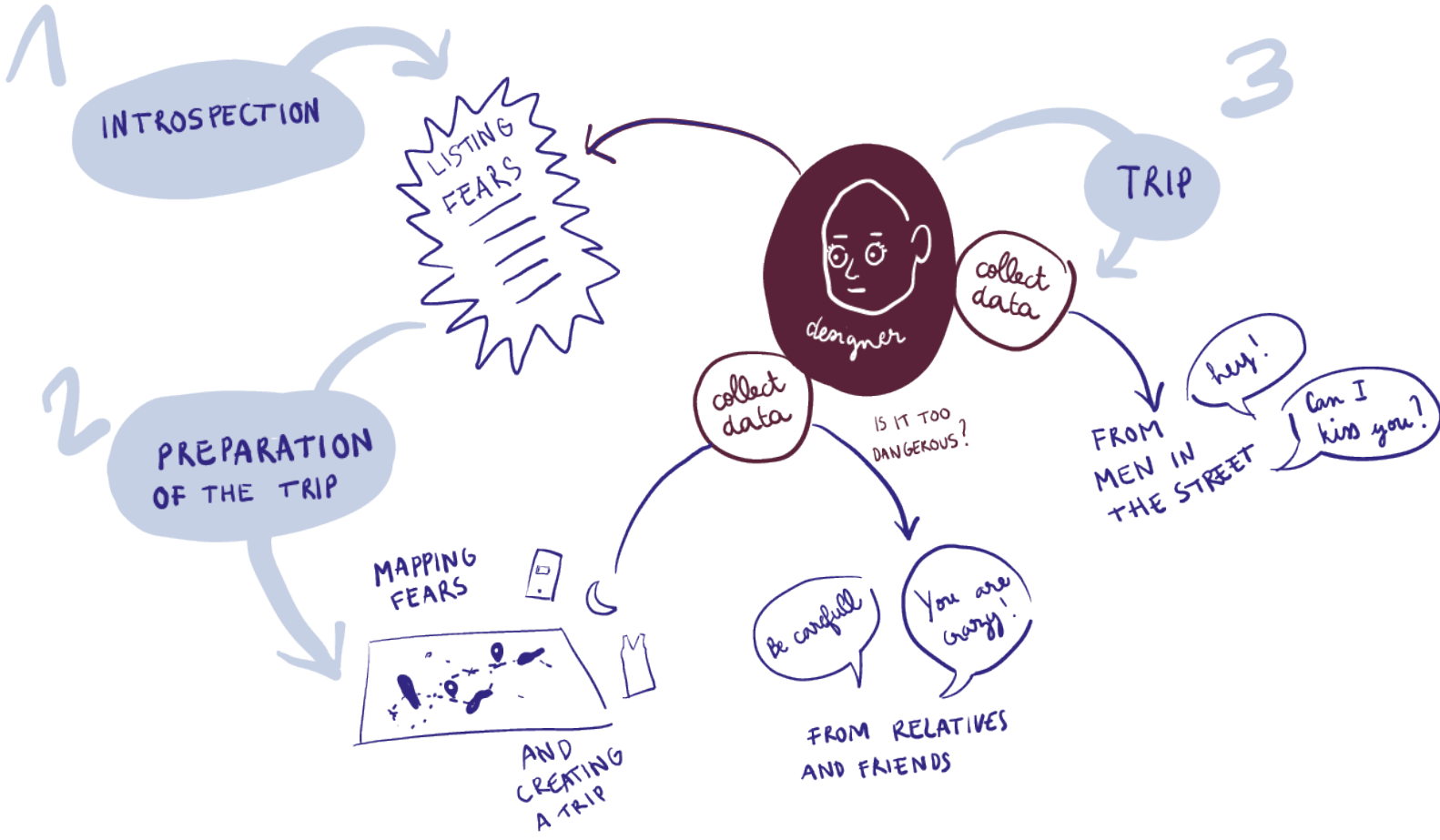

QUESTIONS RAISED BY THE PROBE

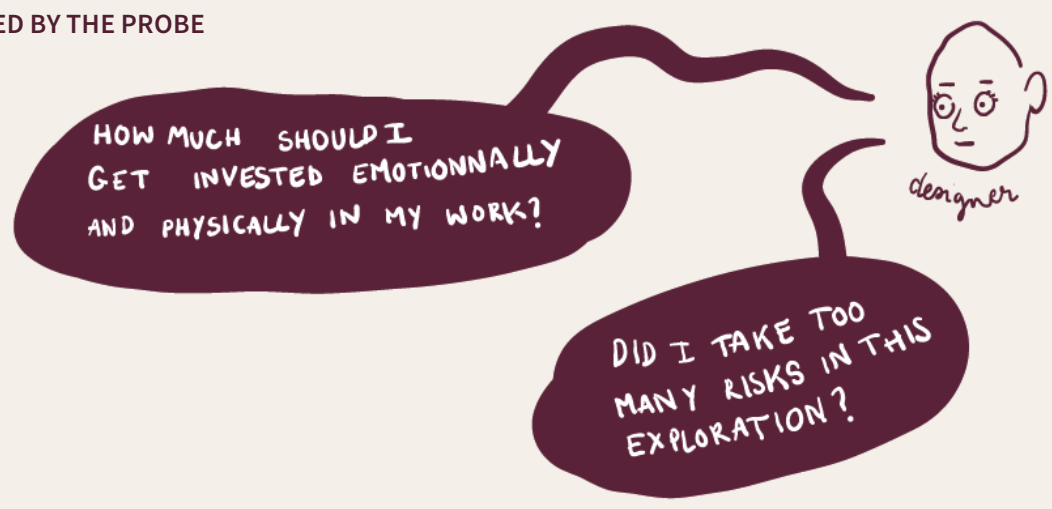

The first author created the probe to explore aspects of gendered fears which impact her daily activities by introspectively trying to reveal her own tactics for feeling or for being safe in the streets.

As she explained her project, and presented her plan, expressions of concerns revealed how fear of sexual assaults were largely focused on certain urban areas, whereas they are more likely to happen within a person close social circle.

1 She started by listing her fears and tactics to feel safe especially alone at night (eg. having her phone charged, avoiding some streets, not wearing certain clothes).

2 She then mapped her fears and created specific personal instruction she knew would be challenging enough for provoking strong emotions before and during the trip. The mapping exercise was a good way for her to choose the path she would take at night and to reflect on her boundaries she was planning to overcome. The map became an object of mediation with other people before the trip by facilitating comments and worries about it. It was interesting to note which aspects of the instructions fostered the most reactions. For example, the fact that she would do this experience without a phone to call for help was something which seemed to worry people considerably. This might be interesting data for designers as a way to reflect on the place of phones in women's safety.

3 To her surprise, the trip in itself didn't place her in any unusual and out of control situations. Avoiding her safety tactics led her to accept to speak to men who approached her, but such situations were already familiar to her, because they happen independently of any tactics women try to set up.

This led to numerous discussions on whether this could be seen as an emancipatory exercise, and to what extent the designer should be engaged in her topic. It also raised the question of whether the probe has to be used - and not just discussed - to efficiently reflect. 


\section{STREET HARASSMENT AND DESIGN RESEARCH GUIDES}

\section{Design methods in question}

During our investigation of design research in urban planning, we found a widespread use of activity sheets, very simple actions designers should engage in to better understand their users. These especially focused on short term observations, sometimes titled ethnography.

\section{The problem}

These activity sheets tend to commodify the ethnographic method and design research, an issue previously raised by Crabtree et al. [9]. They often present simple user research strategies as universally applicable, with little regard to the context in which they are applied. Without a reflexive stance and reciprocation, these methods are at best time consuming for participants. Often they are exploitative, i.e. extracting local knowledge from people without designers giving back. At worst they can put participants at risk, as their privacy is not adequately protected or they are put in harm's way by observation practices [11]. Moreover, the knowledge thus generated is less likely to be representative of marginalised groups' perspective [27]

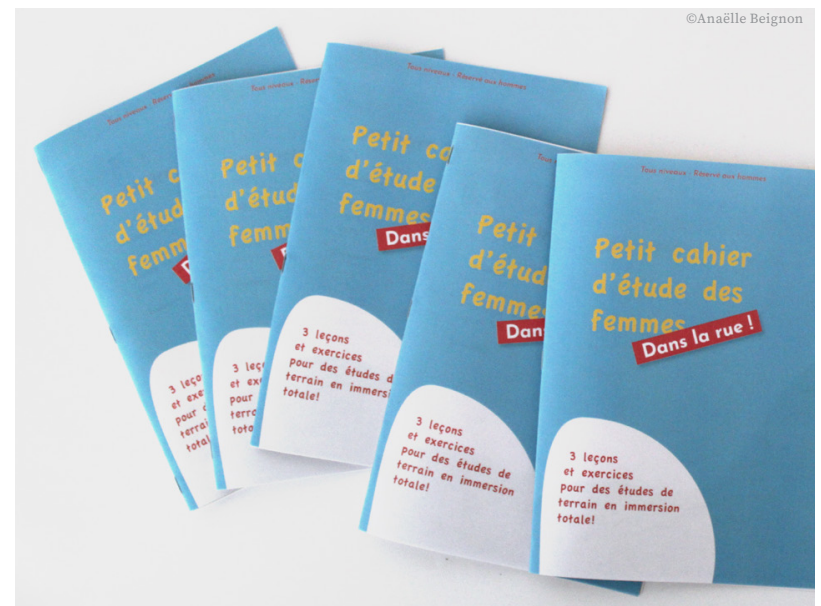

\section{The probe}

We designed an activity book for conducting field work on women in the street. The exercises proposed by the probe present activities that can seem empathetic on a cursory reading, however the way they have to be conducted turns people into street harassers. The activity book takes the playful form of a summer homework notebook with a series of three increasingly breaching exercises: Analyzing women gaze in public transport, observing women reactions to being

followed at various distances and angles, and grading reactions to spontaneous compliments and catcalling.

\section{First exercise:}

Staring at men and women in the street for a few minutes. Drawing on the probe where the subject looks. Is he or she confronting the observer?

\section{Second exercise:}

Following women in the street at night. Colouring the sketches depending on the woman's speed related to the position of the follower.

\section{Third exercise:}

Complimenting or insulting women in different contexts (family, friends, work, street) and rating their reactions from 1 to 5 (negative reaction to positive reaction).

We presented this probe to two male design students. They were interested at first, and one of them found the activities genuinely interesting... We also observed that one of them was feeling uncomfortable to follow a woman at night, but he agreed to do it for the sake of the study we were leading. Because of its harmful potential, we did not ask anybody to conduct the activities. 1) observez dans la rue la direction du regard des hommes et
des femmes seull.e.s. Placez l'iris des yeux des différentes personnes

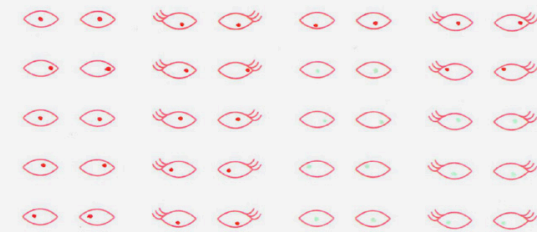

2
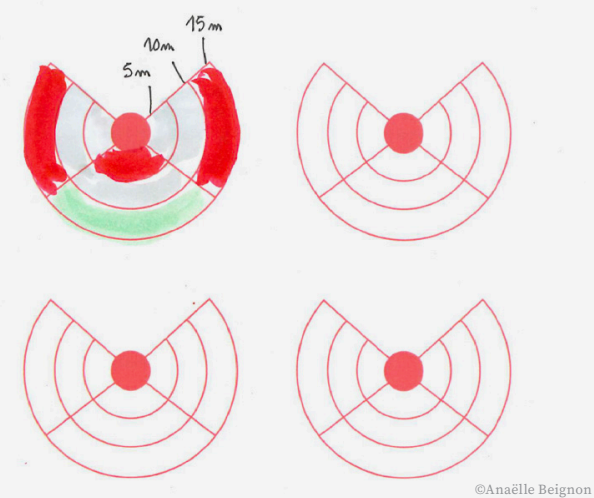

3

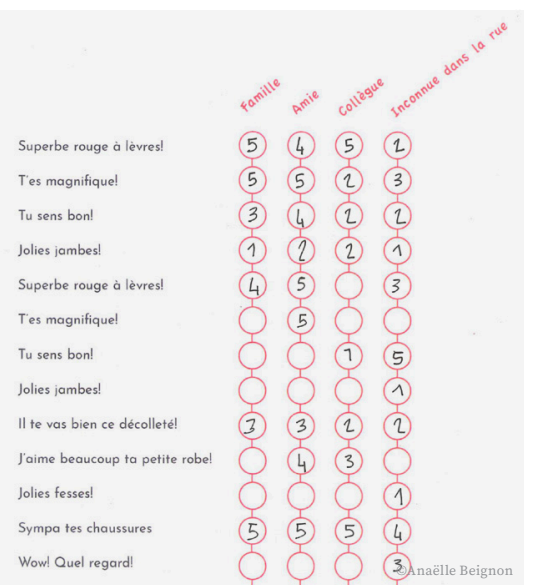




\section{DEPLOYEMENT OF THE PROBE}

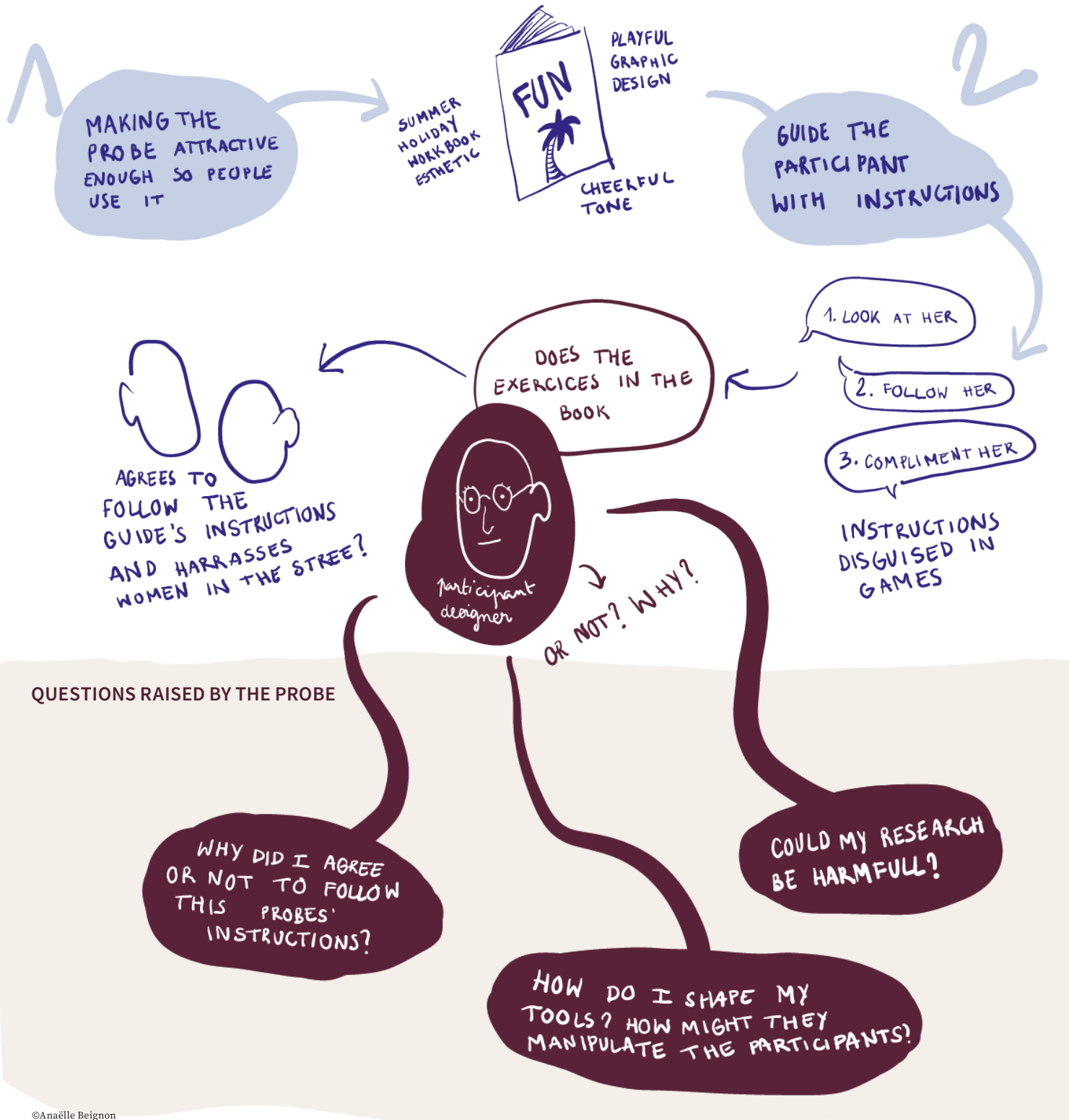

Supporting reflexivity on designers' relation to respondents

With this guide, we examined to what extent design research activity sheets can shape designers'

behaviors, and male designers consciousness of their own behaviors in the street. We sought further to engage discussions on relationships to informants and people participating in their research. What are the direct and indirect costs, and how does it benefit them?

1 The seeming playfulness of the activity book, conveyed through its visual design and editorial tone, reminiscent of a playful summer homework

notebook, seeks to minimize the significance of the problematic practices it encourages.

2 The proposed exercises require the participants to harass women in the street in order to observe the reactions triggered by these types of behaviours. In the exercises, the women observed are not active participants who have a say and control over the process, the outcome, or the framing of the research questions. They are objects of the research. When it comes to complex social issues, simplified observations tend to individualise the issue and seek an individual solution, thereby ignoring complex socio-political structures [23]. Even observing people attentively in the streets at the wrong time or place could generate fears in women, who are more exposed to street harassment. Ignoring such factors while conducting research is problematic.

The ambiguity of this probe regarding whether or not the participants should use it questioned the "ready for use" qualities of design research tools. Specifically for this probe, if the critical dimension is not perceived, it could lead designers to harass women in the street. Because it could still provide "results", the probe could have the potential to strengthen the use of such exploitive tools. 


\section{DISCUSSION}

We created our four tricky design probes to challenge designers' assumptions about gender constructs, design research and co-design tools. This is in line with DiSalvo's proposition that an artifact is adversarial if it can "challenge and offer alternatives to dominant practices and agendas" [9 p.115]. By their reflective and ambiguous nature, the probes tackle politics less as a way to condemn and more as a way to pay attention to the assumptions we have about gender and design tools [4, p.8].

The probes primarily target their creators or facilitators. They prompted deep discussions among co-authors what was to expect from them, whether their impact could be predicted, and whether they "worked". They enabled us to reflect on socio-political issues and their ramifications which might be out of the design field's expertise (presented below).

The quality of the discussions that emerge from the probe about these topics depends on many factors, and is quite challenging to anticipate. One factor is the level of the trickery of the probes. The probes are designed to progressively reveal themselves, taking the form of well-known design tools, but incrementally going to beyond

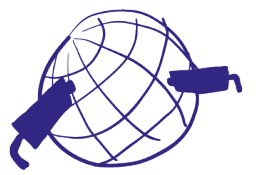

Gender classification and large-scale sensor systems

The probe initially questioned gender classification and sensing systems. The probe surfaced the blending of data collection for research and surveillance purposes. Experiencing first-hand algorithmic training also surfaced how a narrow number of arbitrary and superficial criteria can be used to derive personal traits that may strengthen established stereotypes rather than bringing new insights.

the ethical limits of design practice. Once this limit is passed, the facilitator and participants have an opportunity to reflect on the steps they took, questioning their perspective and design practices currently widely accepted. However, they might also make these forays into ethical gray waters appear acceptable or start unwanted debates.

Another factor is the framing of the discussion. Our experience with the second probe suggests that once engaged in a design activity, it is difficult to push against framing the problem at hand as a problem that can be addressed by design, rather than other policy decisions. This further confirms the issue we had initially identified: designers might have explored the ethical issues for a given topic, but rarely investigate their own methods This could be improved by amplifying, through probes, the known issues at hand. It could further involve participants in designing probes enabling them to understand the designers' values. More importantly, by moving critical design within the design process itself, more designers could be directly involved in critical design work.

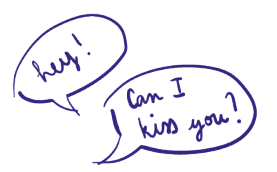

Politics of risk and the convenience of design workshops

The probe initially questioned the perception of risk and manipulation in codesign activities. It surfaced the nuances of control. But it also put forward the challenge in questioning the framing of a design activity as it unfolds.

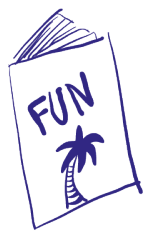

\section{Street harassment and empathy}

The probe initially questioned street harassment and engagement with the field. The probe surfaced questions related to external perceptions of safety and how they may shape designers' own behavior. It also put into light that some socio-political issues that are already perceived by designers may not be discussed or properly considered until some breaching event put them forward.

\section{Street harassment and design guides}

The probe questioned "ready for use" design research tools and how they can become exploitative especially for women. It surfaced how tool use can be connected to the lack of perception or consideration for socio-political issues, such as harassment by a part of the design community. 


\section{CREATING TRICKY DESIGN} PROBES

Our tricky design probes involved five elements:

1. An ethical or socio-political issue to explore. We considered gender in the context of urban planning and urban informatics projects.

2. A design method, tool, or a widespread practice that we want to question.

3. Tricks to deceive participants in order to engage them in the activity and later question their attitude, values, and position. 4. Experimenting with the probe, or staging its use. This requires some level of screenwriting and a "game master" to run the activity tuning the experience of the probe to the reaction of participants. 5. Revelation and confrontation, in the activity or afterwards. This can happen alone, reflexively, or through discussions exploring the questions that the activity arose.

We conducted the revelation and confrontation stage informally. Much could be done to better structure this stage. DiSalvo's work suggests adversarial design tactics that could relevant to build upon [10]: Revealing hegemony, i.e. "exposing and

documenting the forces of influence in society and the means by which social manipulation occurs"; reconfiguring the remainder, i.e., bringing forward and making tangible what is normally excluded; and articulating collectives, i.e., "forging connections between objects, people, space, and actions".

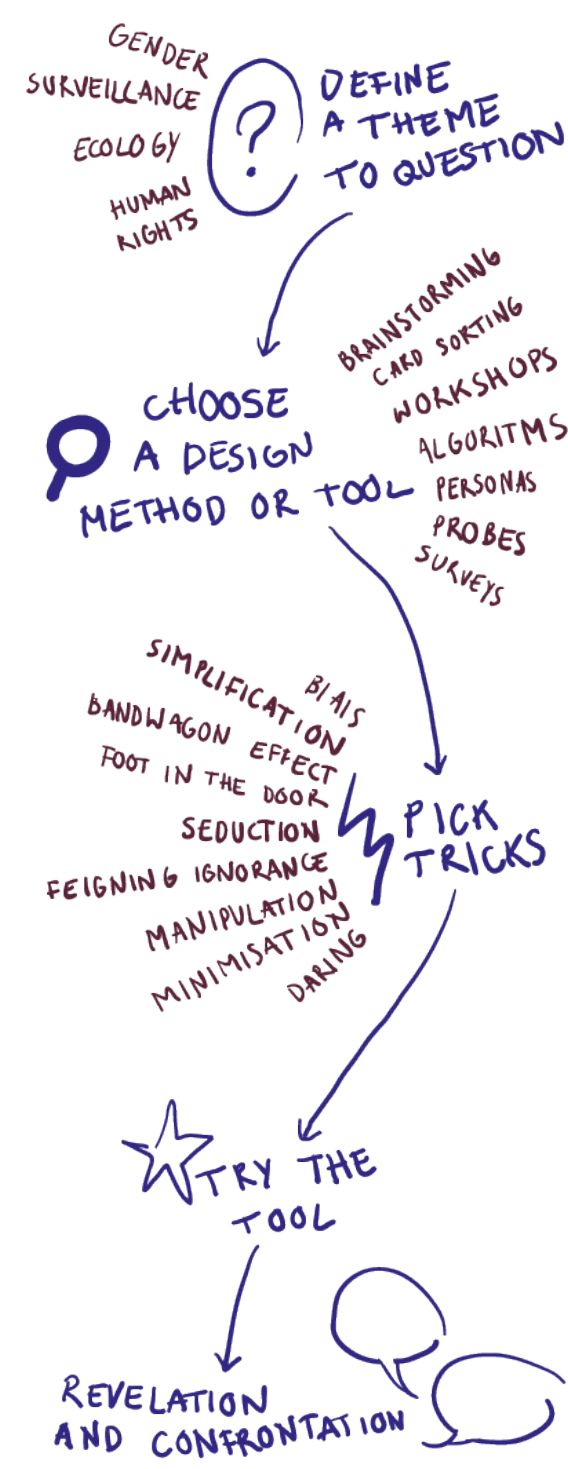

Critical Design discourse has emphasized how processes or tools embed different approaches to Design. For instance, Design Thinking has been criticized for maintaining the status-quo and seeking ncremental solutions from the top, rather than questioning the broader social context [19].

Inspired by Adversarial Design [10], we created probes aimed at designers and other actors engaged in design projects. Tricky Design Probes can be produced by designers to be reflective on their own design practice (eg. Probe 1 has proved to prompt reflexivity through the personal engagement of the designer in the activity) or/and can be shared with the design community as a material for discussion with peers. Their goal is to trigger moments of reflexivity and deliberation on design processes and practices (in our case, ideation). Tricky design probes further question how design relates to socio-political issues (in our case the treatment of gender inequality).

We presented four tricky design probes that can trigger reflexivity on design methods and tools such as (1) the use of machine learning algorithms and sensing systems to define gender identity; (2) the constraints and possible manipulation in co-design workshops, and the politics of risks; (3) the

question of empathy and introspection in harmful contexts; and (4) rapid observational research through guide books with at-risk populations and without proper ethics oversight.

To be effective, tricky design probes, need to be credible, and to some exten let people suspend judgement as they experiment with them. But they should also reach the ethical limits of design practice, possibly even proposing to go beyond them to better highlight the issues at stake. This balance between the believable and the extreme requires the intervention of a mediator. In practice, the first author acted as a sor of game master to obfuscate or reveal the tricks.

The probes can spark reflexive discussions during or after an activity. But they also engage the designer reflexively during their creation. As such, they can offer designers a playful yet critical mirror on their own practices as they investigate complex social issues. 


\section{ACKNOWLEDGEMENTS}

We are extremely grateful to all people who helped us and gave us precious advice during the design of our probes including: France Corbel, Valentine Reynaud, Max Mollon \& Marie Vitali. We warmly thank the participants who tried the probes. We warmly thank the reviewers and the paper chairs for their helpful guidance to improve the pictorial.

This work was partly supported by the ADEME M2I project

\section{REFERENCES}

[1] Sherry R. Arnstein. 1969. A ladder of citizen participation. Journal of the American Institute of planners 35, no. 4: 216-224.

[2] Christian Bason. 2016. Design for Policy. Routledge [3] Jane Bennett. 2010. Vibrant Matter: A Political Ecology of Things. Durham, NC: Duke University Press [4] Cynthia L. Bennett, Burren Peil, and Daniela K. Rosner. 2019. Biographical Prototypes: Reimagining Recognition and Disability in Design. In Proceedings of the 2019 on Designing Interactive Systems Conference (DIS '19). Association for Computing Machinery, New York, NY, USA, 35-47. DOI: https://doi. org/10.1145/3322276.3322376

[5] Erling Björgvinsson, Pelle Ehn, and Per-Anders Hillgren. 2012. Agonistic participatory design: working with marginalised social movements. CoDesign 8, no. 2-3: 127-144.

[6] Erling Björgvinsson, Pelle Ehn, and Per-Anders illgren. 2012. Design things and design thinking: Contemporary participatory design challenges. Design issues 28, no. 3: 101-116.

[7] Kirsten Boehner, Janet Vertesi, Phoebe Sengers, \& Paul Dourish. 2007. How HCI interprets the probes. In Proceedings of the SIGCHI conference on Human factors in computing systems, 1077-1086. ACM.

[8] Marc Böhlen. 2019. AI Ethics in the City. In International Conference on Human-Computer Interaction, 13-27. Springer.

[9] Andrew Crabtree, Tom Rodden, Peter Tolmie, and Graham Button. 2009. Ethnography Considered Harmful'. In Proceedings of the SIGCHI Conference on Human Factors in Computing Systems, 879-888. ACM. DOI:http://dl.acm.org/citation.cfm?id=1518835.

[10] Carl DiSalvo. 2012 Adversarial Design. Mit Press.
[11] Charlotte Aull. Davies. 2012. Reflexive Ethnography: A Guide to Researching Selves and Others. Routledge.

[12] Sarah Fox, Rachel Rose Ulgado, and Daniela Rosner. 2015. Hacking Culture, Not Devices: Access and Recognition in Feminist Hackerspaces. In Proceedings of the 18th ACM Conference on Computer Supported Cooperative Work \& Social Computing (CSCW '15). Association for Computing Machinery, New York, NY, USA, 56-68. DOI:https://doi. org/10.1145/2675133.2675223

[13] William Gaver, Andrew Boucher, Sarah Pennington, Brendan Walker. 2004. Cultural probes and the value of uncertainty. interactions, vol. 11, no 5, p. 53-56.

[14] Kim Halskov, and Peter Dalsgaard. 2006. Inspiration Card Workshops. In Proceedings of the 6th Conference on Designing Interactive Systems, 2-11.

[15] Foad Hamidi, Morgan Klaus Scheuerman, and Stacy M Branham. 2018. Gender Recognition or Gender Reductionism? The Social Implications of Embedded Gender Recognition Systems. In Proceedings of the SIGCHI Conference on Human Factors in Computing Systems, 1-13, ACM.

[16] Christina N. Harrington, Katya Borgos-Rodriguez, and Anne Marie Piper. 2019. Engaging Low-Income African American Older Adults in Health Discussions through Community-based Design Workshops. In Proceedings of the 2019 CHI Conference on Human Factors in Computing Systems (CHI '19). ACM, New York, NY, USA, Paper 593, 1-15.

DOI:https://doi.org/10.1145/3290605.3300823

[17] Christina Harrington, Sheena Erete, and Anne Marie Piper. 2019. Deconstructing CommunityBased Collaborative Design: Towards More Equitable 
Participatory Design Engagements. Proc. ACM Hum.Comput. Interact. 3, CSCW, Article 216 (November 2019), 25 pages.

DOI:https://doi.org/10.1145/3359318

[18] Matthew Holt . 'The Limits of Empathy:

Utopianism, Absorption and Theatricality in Design'.

The Design Journal 14, no. 2 (2011): 151-164.

[19] Natasha Iskander. 2018. Design thinking is

fundamentally conservative and preserves the status quo. Harvard Business Review 5.

[20] Mahmoud Keshavarz and Ramia Maze.

2013. Design and dissensus: framing and staging participation in design research. Design Philosophy Papers 11, no. 1: 7-29.

[21] Shannon Mattern. 2020. Post-It Note City. Places Journal.

[22] Nesta. 'Speculative Design: A Design Niche or a New Tool for Government Innovation?' Accessed 29 January 2020. https://www.nesta.org.uk/blog/ speculative-design-a-design-niche-or-a-new-tool-forgovernment-innovation/.

[23] Tugba Okcuoglu. 2019. Imagining Public Space in Smart Cities: A Visual Inquiry on the Quayside Project by Sidewalk Toronto.

[24] Jess P Roberts, Thomas R Fisher, Matthew J Trowbridge, and Christine Bent. 2016. A Design

Thinking Framework for Healthcare Management and Innovation. In Healthcare, 4:11-14. Elsevier.

[25] Rob Roggema. 2017. Research by design: Proposition for a methodological approach. Urban science 1, no. : 2.

[26] Jennifer A. Rode. 2011. A Theoretical Agenda for Feminist HCI. Interacting with Computers 23, no. 5: 393-400.

[27] Judith Stacey. 1988. Can there be a feminist

ethnography? In Women's studies international forum, vol. 11, no. 1, pp. 21-27. Pergamon.

[28] Lucy Suchman. 2002. Located accountabilities in technology production. Scandinavian journal of information systems 14, 2, 7 . 